Bangladesh J. Bot. 43(2): 131-139, 2014 (September)

\title{
EVALUATION OF CIMMYT MAIZE (ZEA MAYS L.) GERMPLASM BY TROPICAL INBRED TESTERS
}

\author{
UtTaM Chandel*, BS Mankotia AND KS ThaKuR \\ CSK Himachal Pradesh Agricultural University, Shivalik Agricultural Research \\ and Extension Centre, Kangra-176001, India
}

Key words: Zea mays, Testcross, Tropical tester

\begin{abstract}
Twenty five CIMMYT inbreds were crossed with four elite tropical maize testers. Results exhibited that one inbred line tester can select the top best lines from a large number of CIMMYT lines and two testers gave more reliable results than one tester did. However, when line $\times$ environment interaction was significant, selected lines by one tester in one environment were not necessarily same as those selected at another environment indicating thereby that different testers should be used for selecting best inbreds at different environments. This study also showed that inbred lines from different maize heterotic groups did not show any significant differences in identifying best CIMMYT germplasm.
\end{abstract}

\section{Introduction}

The genetic base of maize germplasm throughout the world has been narrowing because of new maize inbred lines and hybrids or varieties have been derived from intercrossing among existing elite materials (Tarter et al. 2004, Goodman 2005). Introducing exotic maize germplasm and the introgression of some useful genes into locally adapted germplasm is an effective way to broaden the genetic base of local maize germplasm and to create new superior inbred lines for hybrid maize development (Albrecht and Dudley 1987, Fan et al. 2008). The overwhelming opinion among maize breeders with exotic germplasm experience is that inbred lines or hybrids are more promising source materials than populations with no history of inbreeding (Goodman 1999).

During the past decade, the CIMMYT germplasm has become one of the best sources of genetic diversification across the world (Aguiar et al. 2008, Nelson and Goodman 2008). The genetic diversity is the basis for a successful maize breeding programme (Melani and Carena 2005). The germplasm introduced from CIMMYT has been a great resource for improving tropical germplasm (Yuan et al. 2002, Xia et al. 2005). However, the questions that need to be answered are: how to test a large number of materials, how many testers should be used and how many test environments should be used. Another important issue is whether results obtained at one environment are different from the results obtained at another environment. Keeping in view these aspects in mind, the present study was undertaken to determine the optimum number of inbred testers needed to select best lines from CIMMYT inbred lines, to test different inbred testers at different environments and to test the selection efficiency of testers belonging to different heterotic groups.

\section{Materials and Methods}

The material for present investigation was developed during Kharif 2011 at Research Farm of Shivalik Agricultural Research and Extension Centre, Kangra. The 25 CIMMYT maize inbred lines, used as female parents, were crossed with four tropical inbred line testers in a line $\times$ tester mating design. In Kharif 2012, these 100 testcrosses along with check HQPM-1 were field tested

*Author for correspondence: <uttam_chandel@yahoo.co.in>. 
for yield performance and their agronomic traits under two environments i.e. irrigated and rainfed conditions of Experimental Farm of SAREC, Kangra, representing subtropical conditions of north western Himalayas. A randomized block design with three replications was used at both environments. Each experimental unit was represented by two rows of $2 \mathrm{~m}$ length with inter and intra-row spacing of $60 \mathrm{~cm}$ and $20 \mathrm{~cm}$, respectively. At maturity, 10 ears from the consecutive plants in middle of row of each experimental unit were harvested for recording data on grain yield/plant $(\mathrm{g})$, ear length $(\mathrm{cm})$, ear diameter $(\mathrm{cm})$, rows/ear and kernels/row. After harvest, the kernels were air dried until a grain moisture content of $15 \%$ was achieved and then 1000 kernel weight $(\mathrm{g})$ was recorded. The related information for all lines used in this study is listed in Table 1. Data collected were analyzed following GLM procedure (SAS 2002).

Table 1. Parental lines used in the present study.

\begin{tabular}{llc}
\hline Lines & Line & Source \\
\hline L1 & CML134 & CIMMYT \\
L2 & CML161 & $"$ \\
L3 & CML166 & $"$ \\
L4 & CML169 & $"$ \\
L5 & CML172 & $"$ \\
L6 & CML224 & $"$ \\
L7 & CML226 & $"$ \\
L8 & CML228 & $"$ \\
L9 & CML229 & $"$ \\
L10 & CML283 & $"$ \\
L11 & CML284 & $"$ \\
L12 & CML290 & $"$ \\
L13 & CML301 & $"$ \\
L14 & CML304 & $"$ \\
L15 & CML325 & $"$ \\
L16 & CML337 & $"$ \\
L17 & CML359 & $"$ \\
L18 & CML408 & $"$ \\
L19 & CML411 & $"$ \\
L20 & CML439 & $"$ \\
L21 & CML452 & $"$ \\
L22 & CML468 & $"$ \\
L23 & CML490 & $"$ \\
L24 & CML493 & $"$ \\
L25 & CML502 & $"$ \\
Testers & " \\
T1 & HKI1040 & Elite inbred line developed at CCS HAU, Maize Research Station, Karnal \\
T2 & CM212 & Elite inbred line developed at VPKAS, Almora \\
T3 & VL341 & $"$ \\
T4 & HKI1105 & Elite inbred line developed at CCS HAU, Maize Research Station, Karnal \\
\hline & & \\
\end{tabular}

\section{Results and Discussion}

The data on field performance from the two environments were subjected to analysis of variance (Table 2). The variations attributable to crosses, testers, lines, crosses $\times$ environment interaction were significant for grain yield and all five yield components. The environmental variance was significant for four components viz., ear length, ear diameter, number of kernels/row and 1000-kernel weight. The variance associated with $\mathrm{L} \times \mathrm{T}$ interaction was significant for grain 
yield and three yield components viz., ear length, ear diameter and 1000-kernel weight. The variance related to line $\times$ environment interaction was significant for all yield components except ear diameter. The variance attributable to tester $\times$ environment interaction was significant for three yield components viz., number of kernel rows/ear, number of kernel/row and 1000-seed weight and that caused by line $\times$ tester $\times$ environment was not significant for grain yield and ear diameter.

Table 2. ANOVA analysis of 100 test crosses for yield and yield components under two environments of mid hill conditions of North-Western Himalayas.

\begin{tabular}{|c|c|c|c|c|c|c|c|}
\hline Source & Df & $\begin{array}{l}\text { Yield/plant } \\
(\mathrm{cm})\end{array}$ & $\begin{array}{l}\text { Ear length } \\
(\mathrm{cm})\end{array}$ & $\begin{array}{l}\text { Ear diam. } \\
\text { rows/ear }\end{array}$ & $\begin{array}{l}\text { No. of } \\
\text { kernels/row }\end{array}$ & $\begin{array}{l}\text { No. of } \\
\text { weight (g) }\end{array}$ & $\begin{array}{l}1000- \\
\text { kernel }\end{array}$ \\
\hline Environments & 1 & 1119.8 & $250.6^{* *}$ & $3.11 * *$ & 0.56 & $2007.7 * *$ & $10390.5^{* *}$ \\
\hline Replications (Env.) & 4 & $4260.2 * *$ & $25.2 * *$ & $0.24 * *$ & 1.29 & $108.2 * *$ & $2410.4 * *$ \\
\hline Crosses & 99 & $1250.2 * *$ & $6.24 * *$ & $0.30 * *$ & $9.14 * *$ & $34.3 * *$ & $3470.3 * *$ \\
\hline Tester & 3 & $3090.2 * *$ & $60.8^{* *}$ & $5.42 * *$ & $217.8^{* *}$ & $340.5^{* *}$ & $13201.2 * *$ \\
\hline Lines & 24 & $2240.9 * *$ & $9.1 * *$ & $0.32 * *$ & $6.66^{* *}$ & $64.7 * *$ & $9107.6 * *$ \\
\hline Line $\times$ tester & 72 & $660.1^{*}$ & $2.6^{*}$ & $0.10 * *$ & 1.28 & 11.4 & $1191.1^{*}$ \\
\hline Cross $\times$ env & 99 & $740.2 * *$ & $3.4^{* *}$ & $0.08 *$ & $1.65^{* *}$ & $24.62 * *$ & $2146.5 * *$ \\
\hline Tester $\times$ env & 3 & 710.4 & 4.7 & 0.22 & $7.26^{* *}$ & $141.7 * *$ & $15840.4 * *$ \\
\hline Line $\times$ env & 24 & $1180.5^{* *}$ & $4.5^{* *}$ & 0.08 & $1.64 *$ & $32.3 * *$ & $1910.6 * *$ \\
\hline Line $\times$ tester $\times$ env & 72 & 604.3 & $3.10 * *$ & 0.07 & $1.42 *$ & $17.58 * *$ & $1620.2 * *$ \\
\hline Error & 396 & 490.6 & 1.99 & 0.06 & 1.03 & 9.48 & 875.4 \\
\hline
\end{tabular}

*Refers to 0.05 significance probability level, **Refers to 0.01 significance probability level.

Criteria to evaluate the efficiency of different testers used for CIMMYT germplasm screening to determine whether or not to a selected line, was first defined. Grain yields from 100 testcrosses were compared with experimental check HQPM-1. Results depicted that grain yield of top 10 testcrosses were statistically at par with the check (data not shown). The CIMMYT lines used to make these 10 top crosses were considered to be the best lines having potential for broadening local maize genetic base and for being utilized for hybrid development. Thereafter, 15 testcross methods were defined and employed for comparison purposes i.e. four testcross methods with one tester for each of the four testers, six testcross methods with two testers selected from all possible combinations of the four testers, four testcross methods with three testers selected from all possible combinations of four testers and one testcross group with all four testers.

Because a good screening method should be able to remove poorest lines and identify most potential line that could be used in a maize breeding programme. The top 10 CIMMYT lines were selected by each of the 15 screening methods. The results are depicted in Table 3 . The selected lines from this table showed that three top lines viz., L21, L23 and L25 were selected by all 15 testcross methods. This result revealed that one inbred line tester had the same efficiency as two or more inbred line testers in selecting top best lines or one inbred line tester might be good enough to identify top best lines from a large number of CIMMYT lines.

The genetic composition of top 10 testcrosses revealed that these were made from only six exotic inbred lines with the four testers. Then the six lines were further compared with the top ten lines selected by each of the 15 testcross methods (Table 3 ). The results are listed in Table 4 with matched lines marked with "S". It was observed that three of the four methods with one tester could correctly select five out of the six best lines. If two or more testers were used, it could correctly select all six top best lines by all methods, except by T23 method (Table 4). These data 


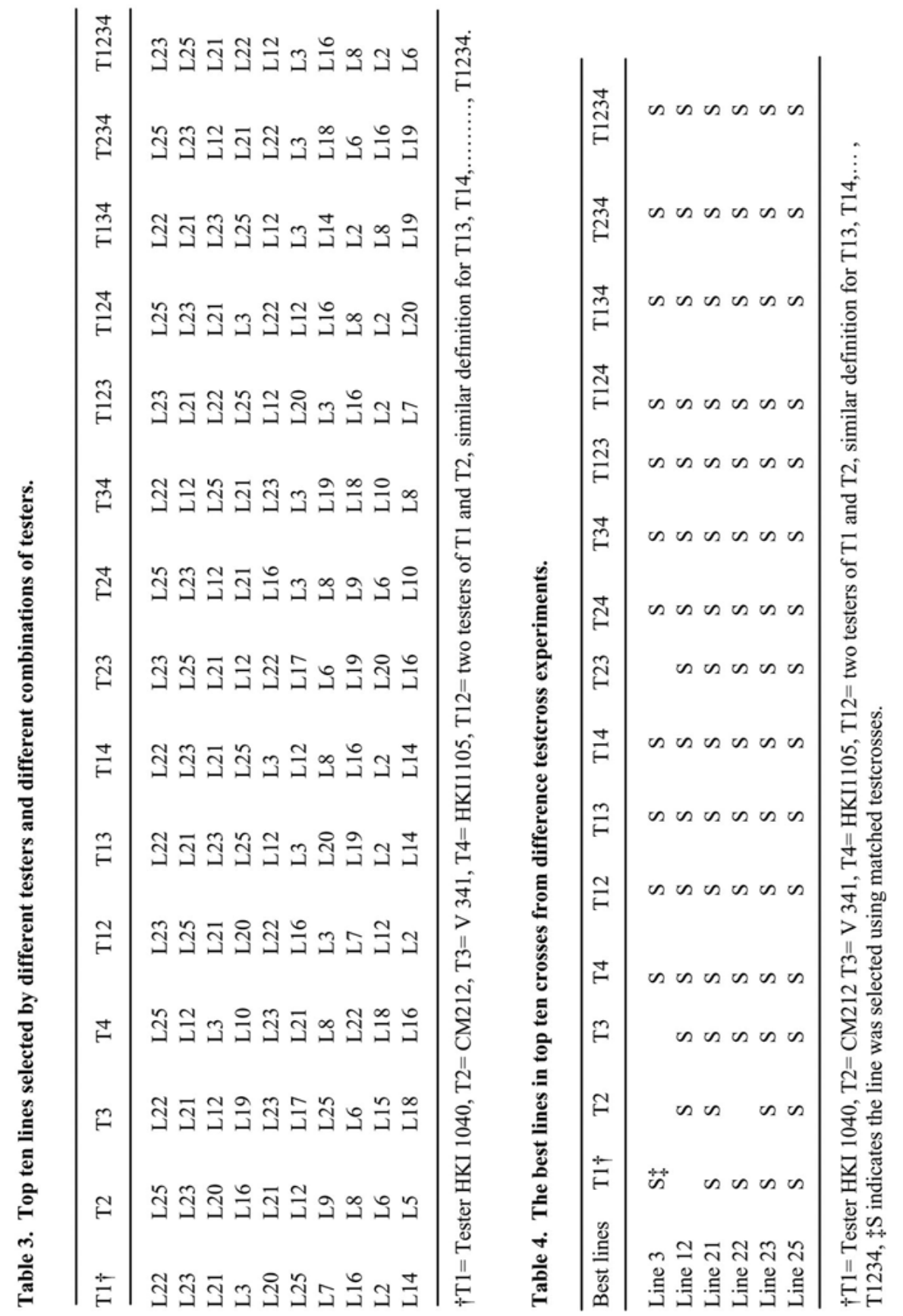


again strongly suggested that one inbred line tester should be good enough for effectively screening a large number of CIMMYT lines, whereas two inbred line testers might be ideal for screening a large number of inbreds if resources are not a constraint. Similar results have been reported earlier in maize (Holland and Goodman 1995).

The testers used in the experiment were selected from two maize heterotic groups. Testers HKI 1040 and HKI 1105 belong to one group that CM 212 and V 341 belongs to another group. It was observed that methods T14 and T23, which employed two testers from same heterotic group, produced non-consistent results (Table 4). T14 method selected all top six best lines and method T23 missed one of the six best CIMMYT inbreds, whereas when two testers from different

Table 5. The ranks of grain yields of 25 lines crossed with the four testers.

\begin{tabular}{lllll}
\hline Line† & HKI1040 & CM212 & V 341 & HKI1105 \\
\hline Line 1 & 3 & 3 & 2 & 12.5 \\
Line 2 & 17 & 13 & 13 & 12.5 \\
Line 3 & 22 & 12 & 11 & 23 \\
Line 4 & 6 & 6 & 14 & 7 \\
Line 5 & 2 & 16 & 10 & 10.5 \\
Line 6 & 10 & 17 & 18 & 15 \\
Line 7 & 19 & 14.5 & 7 & 4 \\
Line 8 & 14 & 18 & 9 & 19 \\
Line 9 & 12 & 19 & 4 & 9 \\
Line 10 & 8 & 9 & 8 & 22 \\
Line 11 & 13 & 11 & 12 & 8 \\
Line 12 & 15 & 20 & 23 & 24 \\
Line 13 & 5 & 1 & 3 & 3 \\
Line 14 & 16 & 7 & 15 & 14 \\
Line 15 & 4 & 5 & 17 & 6 \\
Line 16 & 18 & 22 & 5 & 16 \\
Line 17 & 7 & 14.5 & 20 & 5 \\
Line 18 & 11 & 2 & 16 & 17 \\
Line 19 & 9 & 10 & 22 & 10.5 \\
Line 20 & 21 & 23 & 6 & 2 \\
Line 21 & 23 & 21 & 24 & 20.5 \\
Line 22 & 25 & 8 & 25 & 18 \\
Line 23 & 24 & 24 & 21 & 20.5 \\
Line 24 & 1 & 4 & 1 & 1 \\
Line 25 & 20 & 25 & 19 & 25 \\
\hline
\end{tabular}

$\dagger$, see detail information for each line in Table 1.

Table 6. Correlation coefficients of ranks of grain yields of 25 lines with the four testers.

\begin{tabular}{cllll}
\hline & HKI1040 & CM212 & V 341 & HKI1105 \\
\hline $\begin{array}{l}\text { HKI1040 } \\
\text { Probability }\end{array}$ & 1 & & & \\
CM212 & 0.5924 & 1 & & \\
Probability & 0.0018 & & & \\
V 341 Probability & 0.3962 & 0.2351 & 1 & \\
HKI1105 & 0.0499 & 0.0258 & & \\
Probability & 0.5065 & 0.3764 & 0.4710 & 1 \\
& 0.0098 & 0.0636 & 0.0175 & \\
\hline
\end{tabular}




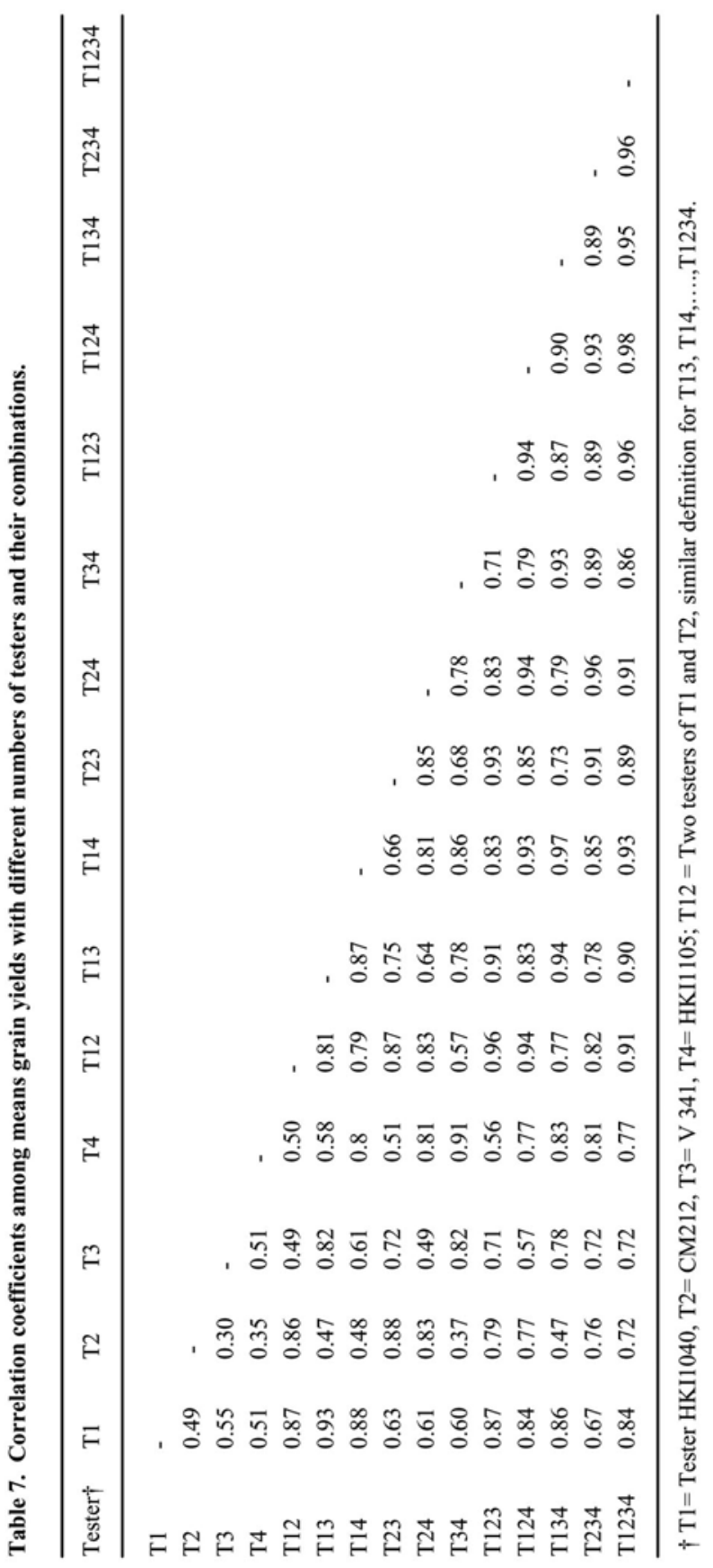




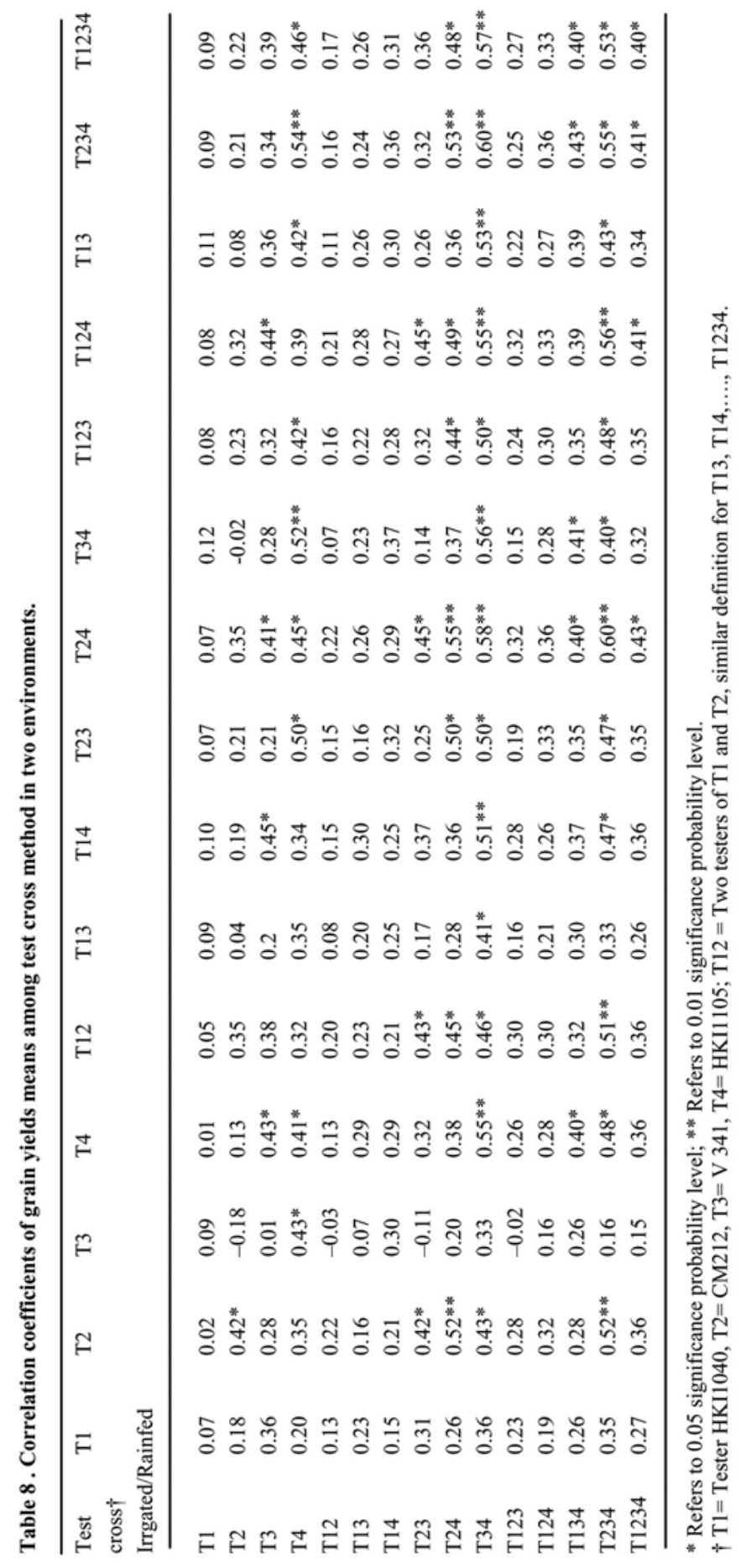


heterotic groups were used, all top six exotic CIMMYT inbreds were selected. To further examine the testers from different heterotic groups had the same or different screening effects, the means of grain yield of 25 CIMMYT inbreds grouped by four testers was calculated. Thereafter, grain yield was ranked (Table 5). The results from Table 5 showed that order of grain yield for each tester group was not consistent. The correlation coefficients of ranks of grain yield among testers were statistically significant for the coefficients (Table 6). The correlation coefficients of ranks of grain yield for testers of CM 212 and VL 341 were lowest. These results failed to reach on concrete conclusion whether testers from different heterotic group would be better than those selected from same heterotic group.

The correlation coefficients among the mean grain yield of 25 CIMMYT inbreds for the 15 top cross methods were also determined (Table 7). All correlation coefficients without common subscription(s) were highly significant $(\mathrm{p} \geq 0.1)$ and because these highly correlated coefficients and had no autocorrelation bias, thereby indicated that the mean grain yields of 25 inbreds among these different testcross methods were highly correlated. In other words, whether one inbred line tester or two inbred line testers or four testers were used, the relative performance of these CIMMYT inbreds were observed similar. This result further suggested that one inbred line tester should be good enough for screening large number of CIMMYT inbreds. Similar results have been reported earlier in maize (Lie et al. 2007).

Because line $\times$ environment interaction was significant, the best line selected in one environment would be selected in another environment by testing correlation coefficients among mean grain yields of the 25 CIMMYT inbreds with 15 different testcross methods (Table 8 ). The Table 8 showed that most of the coefficients were not significant, indicated that inbreds performance in one environment was different or not correlated to that obtained from another environment. This was true when same tester was used (on diagonal). These results suggested that when interaction between line $\times$ environment was significant, the CIMMYT inbreds performance should be evaluated in multiple environments or multiple years or both. Similar results were reported earlier in maize (Sharma et al. 1967).

From this study it might be concluded that one inbred line tester would effectively select most, if not all, of top best lines from large number of CIMMYT inbreds and could be used for preliminary screening. Two inbred line testers should have better chance of identifying best top performing lines. It is not clear if it would be beneficial to use two inbreds from different heterotic groups. When line $\times$ environment interaction is significant, multiple years or environments testing are needed to properly screening of CIMMYT inbreds and different testers may be needed for this screening purpose.

\section{References}

Aguiar CG, Schuster I, Amaral AT, Scapim CA and Vieira ESN 2008. Heterotic groups in tropical maize germplasm by test crosses and simple sequence repeat markers. Genet. Mol. Res. 7: 1233-1244.

Albrecht B and Dudley JW 1987. Evaluation of 4 maize populations containing different proportions of exotic germplasm. Crop Sci. 27: 480-486.

Fan XM, Chen HM, Tan J, Xu CX, Zhang YM, Huang YX and Kang MS 2008. A new maize heterotic pattern between temperate and tropical germplasms. Argon. J. 100: 917-923.

Goodman MM 1999. Broadening the genetic diversity in maize breeding by use of exotic germplasm. pp. 139-148. In: S Pandey (Ed.), the genetic and exploitation of heterosis in crops.

Goodman MM 2005. Broadening the U.S. maize germplasm base. Maydica 50: 203-214.

Holland JB and Goodman MM 1995. Combining ability of tropical maize accessions with US germplasm. Crop Sci. 35: 767-773. 
Li MS, Li XH, Deng LW, Zhang DG, Bat L and Zhang H 2007. Comparisons of four testers in evaluating 27 CIMMYT and Chinese maize populations. Maydica 52: 173-179.

Melani MD and Carena MJ 2005. Alternative maize heterotic pattern for the Northern Corn Belt. Crop Sci. 45: $2186-2194$.

Nelson PT and Goodman MM 2008. Evaluation of elite exotic maize inbreds for use in temperate breeding. Crop Sci. 48: 85-92.

SAS Institute 2002. SAS/STAT 9 User's Guide. SAS Inst, Cary, NC.

Sharma D, Tandon JP and Batra JN 1967. Effect of tester on combining ability estimates of maize germplasm complexes. Euphytica 16: 370-376.

Tarter JA, Goodman MM and Holland JB 2004. Recovery of exotic alleles in semi-exotic maize inbreds derived from crosses between Latin American accessions and a temperate line. Theor. Appl. Genet. 109: 609-617.

Xia XC, Reif JC, Melchingre AE, Frisch M, Hoisington DA and Warburton ML 2005. Genetic diversity among CIMMYT maize inbred lines investigated with SSR markers. Crop Sci. 145: 2573-2582.

Yuan LX, Zhang SH, Warburton M, Li XH and Li MS 2002. Assessment of genetic similarities among maize inbred lines using SSR markers. In: Proc. 8th Asian Regional Maize Workshop. PH Zaidi (Ed.), pp. $50-58$.

(Manuscript received on 25 August, 2013; revised on 7 November, 2013) 